
\title{
CIÊNCIA'NATURA
}

\section{ZONEAMENTO AGROCLIMÁTICO PARA O PLANTIO DO ARROZ NA MESORREGIÂO CENTRAL DO ESTADO DO MARANHÂO}

\author{
Agroclimatic zoning for rice planting in the central mesoregion of the Maranhão State
}

${ }^{1}$ Italo Ramon Januário, ${ }^{2}$ Ronaldo Nascimento Menezes e ${ }^{1}$ Osmar Toledo Bonfim

${ }^{1}$ Universidade Federal de Alagoas, Brasil

${ }^{2}$ Universidade Estadual do Maranhão, Brasil

\section{Resumo}

O objetivo deste trabalho foi realizar um zoneamento de risco climático para definir as melhores épocas de plantio de arroz na região central do estado do Maranhão. Utilizou-se dados do Instituto Brasileiro de Geografia e Estatística; Série histórica de precipitação e temperatura obtidas da Agência Nacional de Águas e Instituto Nacional de Meteorologia. O zoneamento agroclimático de risco foi efetuado utilizando o programa SARRAZON. Definiu-se o risco climático para semeadura do arroz da seguinte forma: ISNA $>0,65$ - Baixo risco climático, região favorável ao plantio; 0,55 $<$ ISNA < 0,65 - região intermediária; ISNA $<0,55$ - Alto risco climático, região desfavorável ao plantio. Para a Região $\mathrm{R} 7 \mathrm{em}$ solos com CAD de $30 \mathrm{~mm}$, o período vai desde o primeiro decêndio de dezembro ao primeiro decêndio de fevereiro. E para solos com CAD de $40 \mathrm{~mm}$, a melhor época de plantio vai desde o terceiro decêndio de novembro ao terceiro decêndio de fevereiro. Para a região homogênea $R 9$ em solos com CAD de 20 e $30 \mathrm{~mm}$ vão desde o terceiro decêndio de novembro ao segundo decêndio de janeiro. Para solos com CAD de $40 \mathrm{~mm}$, a semeadura vai desde o terceiro decêndio de novembro ao terceiro decêndio de janeiro.

Palavras Chave: Zoneamento de risco climático. Balanço hídrico. Agrometeorologia

\section{Abstract}

The aim of this study is to accomplish a climatic risk zoning to define the best season to planting rice in the central region of Maranhão State. There were used data from the Brazilian Institute of Geography and Statistics; Historical series of precipitation and temperature obtained from the National Water Agency and National Institute of Meteorology. The agroclimatic risk zoning was accomplished using the SARRAZON program. The climatic risk for sowing rice was defined as follows: ISNA>0.65 - Low climatic risk, favorable region to the planting; 0.55 $<I S N A<0.65$ - intermediate region; ISNA <0.55 - High climatic risk, unfavorable region. For the R7 Region in soils with CAD $30 \mathrm{~mm}$, the period ranges from the first ten-day of December to the first ten-day of February. And for soils with CAD 40mm, the better planting season is from the third ten-day of November to the third ten-day of February. For the R9 homogeneous region in soils with CAD of 20 and $30 \mathrm{~mm}$, the results showed since the third ten-day of November to the second ten-day of January. For soils with CAD $40 \mathrm{~mm}$, the rice sowing ranges from the third ten-day of November to the third ten-day of January.

Keywords: Climatic risk zoning. Water balance. Agrometeorology 


\section{Introdução}

O arroz é considerado o produto de maior importância econômica em muitos países em desenvolvimento, constituindose alimento básico para cerca de 2,4 bilhões de pessoas. É uma das plantas cultivadas mais antigas do mundo. Originário do sudeste da Ásia, provavelmente foi a primeira planta cultivada na Ásia. Foram, certamente, os portugueses que introduziram esse cereal na África Ocidental, e os espanhóis, os responsáveis pela sua disseminação nas Américas (EMBRAPA, 2017). É o único cereal que pode ser cultivado em solos inundados, sendo considerada a espécie com maior potencial de aumento de produção para o combate da fome no mundo

No Maranhão, a introdução do arroz ocorreu no século XVII. Nesta região, o arroz vermelho foi a única variedade cultivada até 1766 quando foi substituída pelo arroz branco da Carolina. Entre os anos de 1768 e 1777, o arroz era o único cereal exportado pelo Brasil, sendo o Maranhão o maior produtor colonial (PEREIRA, 2002). Segundo estudo realizado por Wander e Chaves (2011), o brasileiro consome cerca de $46 \mathrm{~kg}$. ano ${ }^{-1}$ de arroz beneficiado, reforçando sua importância de alimento básico da dieta da população. Os autores destacam que, na ordem decrescente, a região brasileira que mais consome o arroz no domicílio familiar é a região Centro-Oeste, seguida pelas regiões Norte, Nordeste, Sudeste e Sul.

Segundo a Companhia Nacional de Abastecimento (CONAB, 2016), a plantação de arroz no Maranhão é realizada normalmente em dezembro e janeiro, a depender do tipo de manejo utilizado, irrigado ou sequeiro, e do regime de chuvas. Ainda de acordo com o autor, em seu primeiro levantamento da safra 2017/2018 para a Região Nordeste, a expectativa é de redução da área plantada com arroz, principalmente nas áreas de sequeiro, e para o estado do Maranhão, a estimativa é de que a área cultivada seja a mesma da safra anterior, 258 mil toneladas.

De acordo com Sentelhas e Monteiro (2009), a agricultura é considerada a atividade econômica mais dependente das condições climáticas. Os elementos meteorológicos afetam não só os processos metabólicos das plantas, diretamente relacionados à produção vegetal, como também as mais diversas atividades no campo. Dentre os elementos meteorológicos, a temperatura é um dos componentes climáticos que mais interferem no desenvolvimento do arroz, uma vez que, quando ela é baixa $\left(<17^{\circ} \mathrm{C}\right)$ pode acarretar o abortamento de flores (esterilidade). Além da má germinação, retarda o processo de crescimento e reduz o número de perfilhos. São igualmente prejudiciais temperaturas acima de $40^{\circ} \mathrm{C}$.

Segundo Minuzzi et al. (2015), qualquer mudança no clima afeta o zoneamento agrícola, a produtividade de diversas culturas e as técnicas de manejo. Na região tropical, o conhecimento da distribuição de chuvas e da duração do período de disponibilidade de água, em relação à fisiologia das culturas e condições do solo, é pré-requisito essencial para o planejamento e produtividade agrícola. As chuvas afetam a disponibilidade hídrica dos solos, influenciando na absorção de água pelas raízes e o status hídrico das culturas. Somado a isso, o déficit hídrico causa também prejuízos para a economia de uma região, que é dependente das atividades agrícolas. Sua intensidade, duração, época de ocorrência e a interação com outros fatores do rendimento final define o impacto da falta de água sobre a economia da região. $\mathrm{O}$ fator de maior importância na variação do rendimento final das culturas é a variabilidade interanual das condições hídricas do solo que é determinada pela variabilidade das chuvas (CARVALHO, 2010).

Silva e Azevedo (2000) mencionam que o zoneamento de risco climático leva em consideração a variabilidade climática local da precipitação e da evapotranspiração potencial, permitindo definir se uma região é apta ou não para a implantação de uma cultura e a melhor época para plantio. O balanço hídrico é uma ferramenta muito importante na realização do zoneamento agroclimático, tendo o objetivo de minimizar quebras de safra, apontando os períodos de maior exigência da cultura com os períodos de maior disponibilidade hídrica e menor risco de estiagens (LORENÇONI et al., 2010).

A técnica de análise multivariada foi utilizada por Menezes (2009) para definir as regiões homogêneas de precipitação pluvial sobre o estado do Maranhão, e com isso, criar e avaliar indicadores regionalizados de rendimento agrícola para as culturas de soja, arroz e milho, os quais foram constituídos das variáveis precipitação, temperaturas média, máxima e mínima do ar, evapotranspiração potencial e real, excesso e deficiência hídrica, armazenamento e oceanográfica (anomalias de Temperatura da Superfície do Mar do Pacífico e Atlântico Tropical).

Por estas razões, surge a necessidade de realizar a caracterização da região quanto ao aspecto agroclimático visando estabelecer períodos favoráveis ao cultivo, avaliando o balanço hídrico, excesso e deficiência hídrica, retirada e reposição hídrica, evapotranspiração potencial e real e o armazenamento de água no solo (CAD) como proposto por Thornthwaite e Mather (1955). Diante disso, o objetivo deste trabalho foi realizar um zoneamento de risco climático para a definição das melhores épocas de plantio da cultura do arroz na Região Central do estado do Maranhão. 


\section{Metodologia}

O estado do Maranhão está situado no extremo oeste da região Nordeste do Brasil, entre $1^{\circ}$ e $10^{\circ}$ de Latitude Sul, e $41,5^{\circ}$ e 48, $6^{\circ}$ de Longitude Oeste, com uma área de $331.983 \mathrm{Km}^{2}$. É limitado ao Norte pelo Oceano Atlântico; a Leste e Sudeste pelo estado do Piauí; ao Sul e Sudoeste pelo estado de Tocantins e a Oeste pelo estado do Pará. O trabalho abrangeu a Região Central do estado do Maranhão, como mostra a figura 1 abaixo.

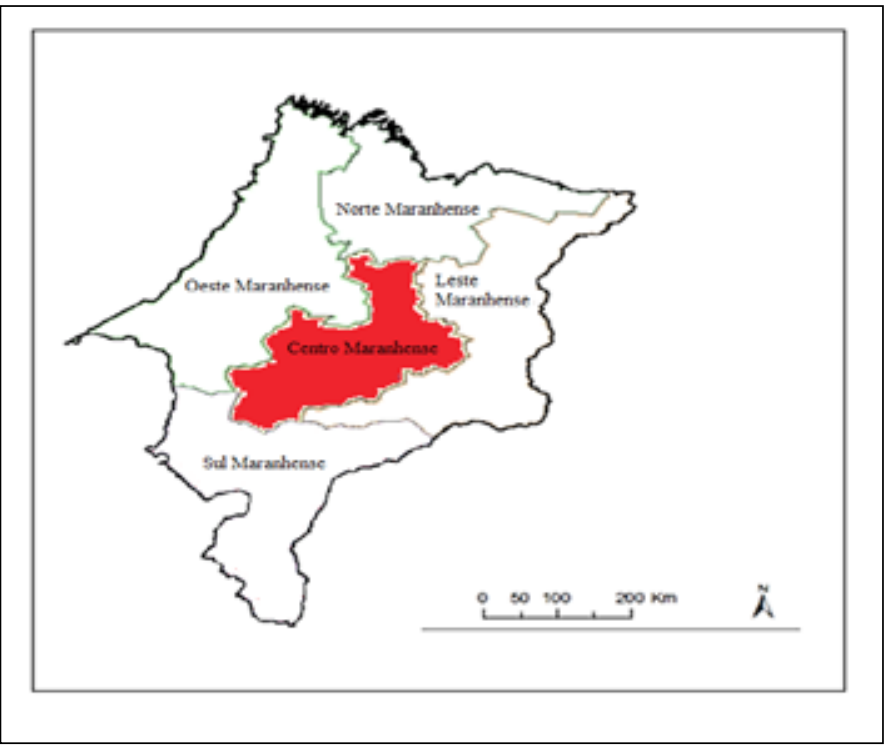

Figura 1- Localização da área de estudo

O estado do Maranhão foi dividido em 10 regiões homogêneas de precipitação, descrito por Menezes (2009), como mostra a figura 2:

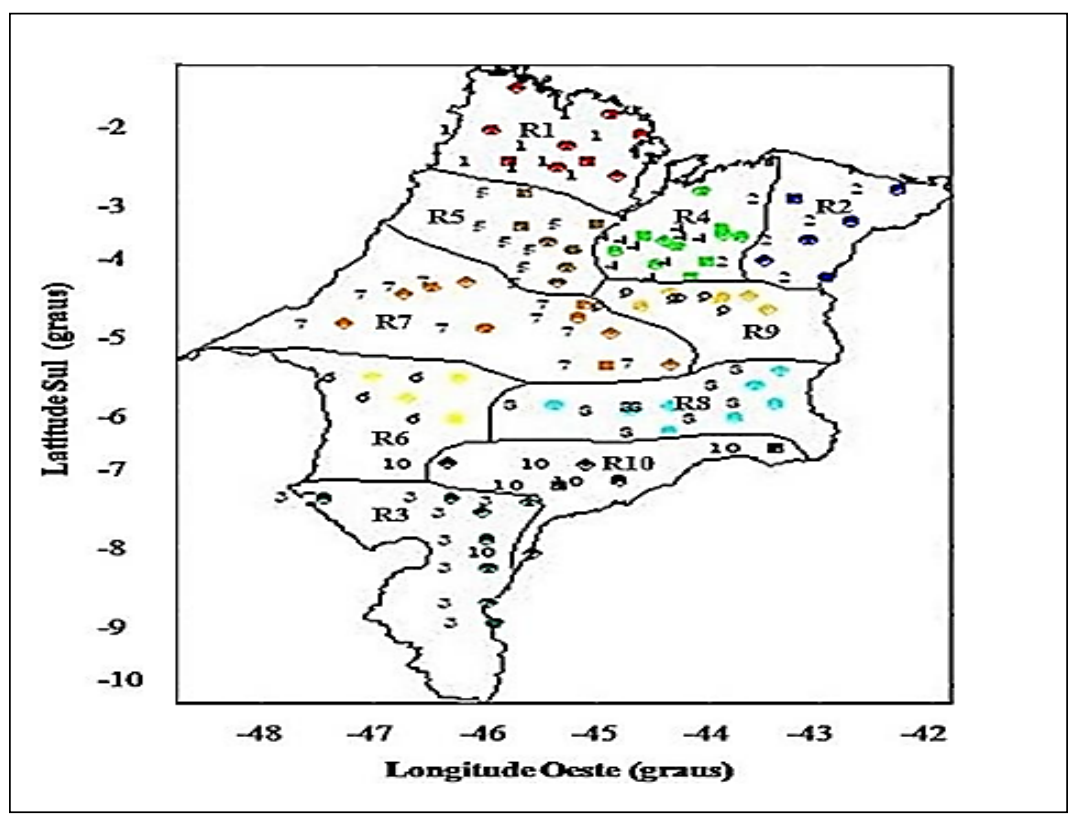

Figura 2 - Extraído de Menezes (2009). Distribuição espacial das regiões homogêneas de precipitação no estado do Maranhão.

Na região Central, se localiza duas regiões homogêneas de precipitação. A região homogênea de precipitação (R7) abrange uma extensa área no centro-oeste maranhense, cobrindo principalmente o sul da microrregião de Pindaré. Representa uma região de floresta densa, onde o total pluviométrico médio anual alcança $1400 \mathrm{~mm}$, sendo os maiores totais observados entre os meses de janeiro a abril (MENEZES, 2009). No centro-leste do estado, tem-se a região homogênea de precipitação (R9) que abrange as microrregiões de Codó e Coelho Neto, com alturas pluviométricas médias de $1544 \mathrm{~mm}$ anuais. 
Utilizou-se uma série histórica de precipitação pluviométrica, temperatura média do ar, do ano de 1980 a 2010 (total de 31 anos), no estado do Maranhão, obtidas da Agência Nacional de Águas (ANA) e Instituto Nacional de Meteorologia (INMET), com auxílio do Núcleo Geoambiental (NUGEO) da Universidade Estadual do Maranhão (UEMA). Para cada região homogênea de precipitação, foram selecionados três postos pluviométricos que apresentassem uma série consistente de dados e de maior precisão. Os dados de chuva e de temperatura foram organizados em decêndios (totais de chuvas acumulados de 10 em 10 dias). Foi utilizado planilha eletrônica adequada para a organização dos dados.

Para a estimativa da Evapotranspiração potencial (ETP), utilizou-se o programa de Sentelhas e Rolim utilizando o procedimento proposto por Thornthwaite (1948), o qual tem a vantagem de necessitar apenas dos dados de temperatura média do ar dos períodos e da latitude local. Esse método dá resultados confiáveis entre as latitudes de $40^{\circ} \mathrm{N}$ e $40^{\circ} \mathrm{S}$ (DOURADO NETO E VAN LIER, 1991. Com os dados de chuva e evapotranspiração potencial, foi possível determinar a estação de crescimento pelo método descrito por (DOORENBOS E KASSAM, 1979. Através deste método, foi possível determinar o início e fim da estação chuvosa, de crescimento e úmida. A estação chuvosa e de crescimento começa quando os totais decendiais de chuva for maior que a metade da evapotranspiração potencial. Quando os totais decendiais de chuva for menor que a metade da evapotranspiração potencial, termina a estação chuvosa, porém a estação de crescimento só termina alguns dias após, quando as reservas de águas associadas à Capacidade de Água Disponível (CAD) no solo se esgotarem.

Para o zoneamento agroclimático de risco utilizou-se o programa computacional Sarrazon- Sistema de Análise Regional dos Riscos Agroclimáticos (BARON et al., 1996), para o cálculo do balanço hídrico, aplicado aos dados em escala temporal decendial. O Sarrazon é um modelo aprimorado do BIPZON (utilizado em vários zoneamentos culturas agrícolas) e seus parâmetros de entrada são: a precipitação pluviométrica e a evapotranspiração potencial, determinada pelo método de Thornthwaite (1948).

Os balanços hídricos foram elaborados considerando a estação de cultivo de cada região homogênea. Para a caraterização do risco climático, foi utilizado o Índice de Satisfação de Necessidade de Água (ISNA) que é a relação ETr/ETm (Evapotranspiração real/evapotranspiração máxima da cultura), calculado para as fases de floração e enchimento dos grãos. O modelo de simulação do balanço hídrico da cultura (SARRAZON) permitiu a determinação dos valores de evapotranspiração real (ETr) e evapotranspiração máxima da cultura (ETm), com os quais se estimaram os valores dos índices de satisfação das necessidades de água (ISNA) da cultura (equação 1).

$$
\operatorname{ISNA}=\left(\frac{\mathrm{ETr}}{\mathrm{ETm}}\right)
$$

Em que: ISNA - índice de satisfação das necessidades de água (decimal); ETr evapotranspiração real da cultura (mm);ETm - evapotranspiração máxima da cultura $(\mathrm{mm})$.

A ETr expressa a quantidade de água que a planta efetivamente consumiu e a ETm representa a quantidade de água desejável para garantir sua produtividade máxima. Um dos produtos mais importantes do modelo é a relação ETr/ETm, que expressa a quantidade de água que a planta consumiu e a que seria desejada para garantir a sua máxima produtividade. Para a caracterização do risco climático foram estabelecidas três classes da relação Evapotranspiração real (ETr)/Evapotranspiração máxima (ETm) (STEINMETZ et al. (1985):

\section{ISNA > 0,65 - Baixo risco climático, época favorável ao plantio; \\ $\mathbf{0 , 5 5}<$ ISNA $<0,65$ - Médio risco climático, época intermediária; \\ ISNA $<\mathbf{0 , 5 5}$ - Alto risco climático, época desfavorável ao plantio.}

Foram considerados três tipos de solo com diferentes capacidades de armazenamento de água: Solo 1: Baixa Capacidade de Água Disponível (20 mm) - Areia quartzosa e solos aluviais arenosos; Solo 2: Média Capacidade de Água Disponível (30 mm) - Latossolo Vermelho-Escuro $(\operatorname{argila}<35 \%)$ e Latossolo Vermelho-Amarelo; Solo 3: Alta Capacidade de Água Disponível (40 mm) - Podzólicos Vermelho-Amarelo e Vermelho-Escuro (Terra roxa estruturada), Cambissolos Roxos e Latossolos Vermelho-Escuro (Argila > 35\%). Estes critérios de CAD citados acima são os adequados para a cultura do arroz do Maranhão. Foram utilizados os coeficientes culturais para períodos de 10 dias, considerando apenas cultura de ciclo médio.

Tabela 1 - Coeficientes de cultivo (Kc) para a cultura do arroz de sequeiro.

\begin{tabular}{c|c|c|c|c|c|c|c|c|c|c|c|c}
\hline \multirow{2}{*}{ Cultura } & \multicolumn{10}{c}{ Decêndios } \\
\cline { 2 - 13 } & 1 & 2 & 3 & 4 & 5 & 6 & 7 & 8 & 9 & 10 & 11 & 12 \\
\hline Arroz Médio & 0,60 & 0,70 & 0,80 & 1,00 & 1,10 & 1,20 & 1,20 & 1,20 & 1,10 & 0,90 & 0,80 & 0,70 \\
\hline
\end{tabular}


Os valores de ISNA foram obtidos da simulação de balanços hídricos efetuados com uma probabilidade de ocorrência de $80 \%$. Para a simulação foram estipuladas datas precedentes em 30 dias ao plantio e 30 dias pós-colheita para as nove datas de plantio espaçadas em 10 dias (Conforme o Início da estação chuvosa para cada região homogênea), proporcionando maior confiabilidade ao modelo. É importante ressaltar que, por se tratar de um modelo de risco climático, assumiu-se que não existem limitações quanto à fertilidade de solos e danos causados por pragas e doenças, conforme sugerido por Assad et al. (1997).

\section{Resultados}

A região homogênea de precipitação R7 apresentou um período de estiagem, que começa a partir do primeiro decêndio de maio, estendendo-se até o terceiro decêndio de dezembro. A reposição de água no solo começa a partir do segundo decêndio de fevereiro até o primeiro decêndio de abril, como observado na figura 3.

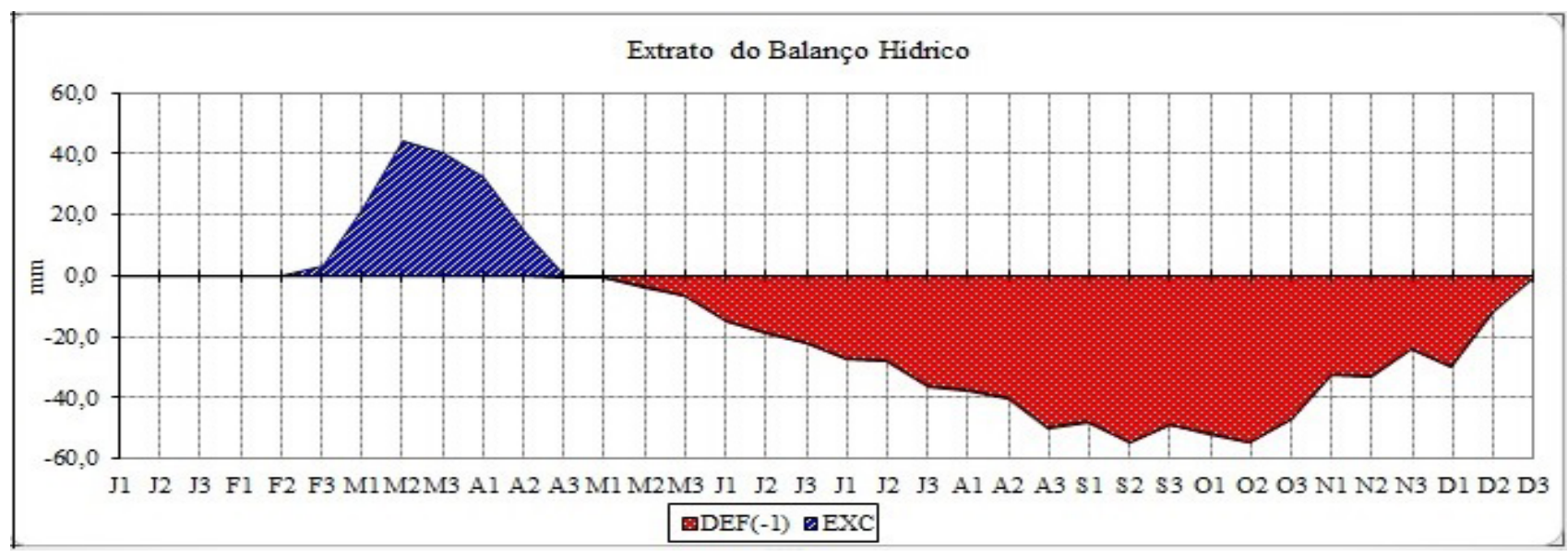

Figura 3- Extrato do Balanço Hídrico Climatológico da região homogênea de precipitação R7, distribuídos em decêndios dos meses de janeiro a dezembro para o estado do Maranhão.

A retirada de água no solo ocorre do primeiro decêndio de maio ao segundo decêndio de setembro, à medida que este vai perdendo água, começa então a deficiência de água no solo, estendendo-se até o segundo decêndio de dezembro (Figura 4). No terceiro decêndio de dezembro começa a reposição de água no solo, que vai até o segundo decêndio de janeiro e o excedente de água estende-se até o segundo decêndio de maio.

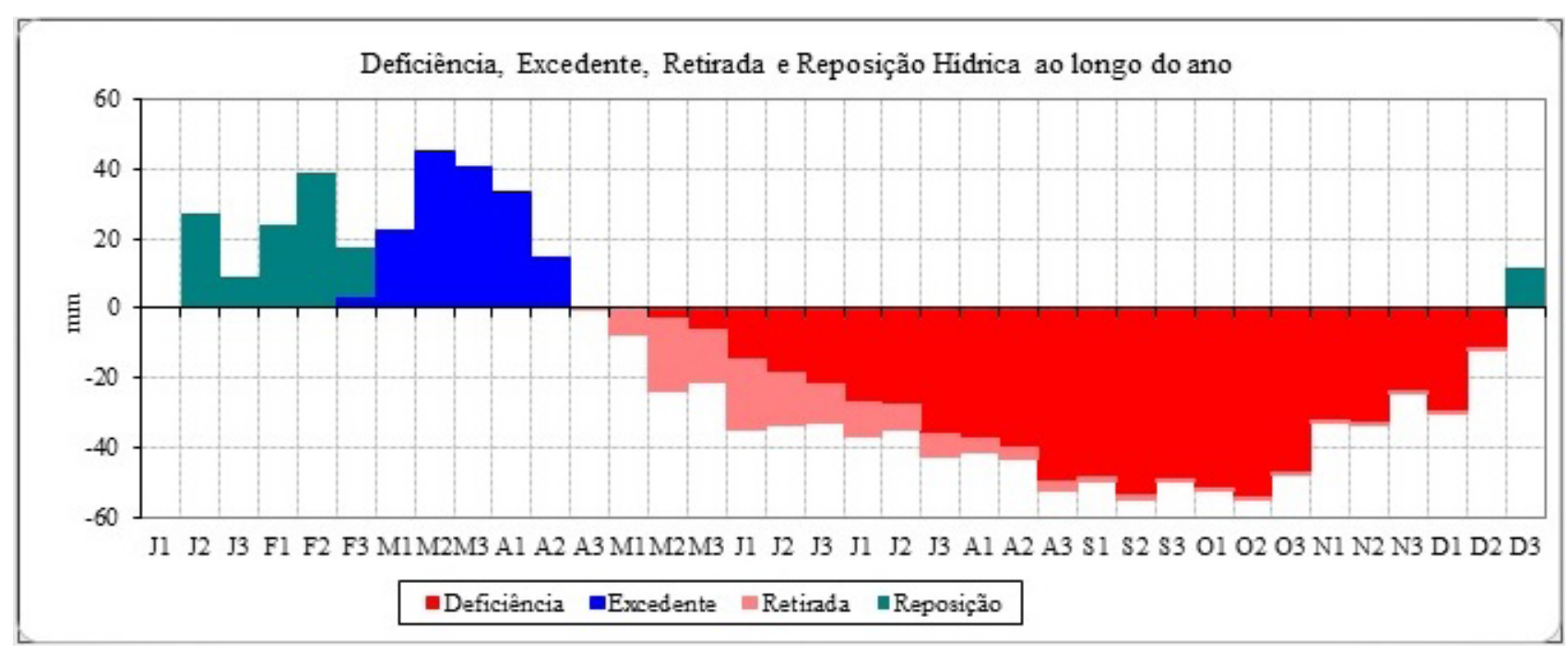

Figura 4 - Deficiência, Excedente, Retirada e Reposição hídrica ao longo dos anos na região homogênea de precipitação R7, separados em três Decêndios, dos meses de janeiro a dezembro, no estado do Maranhão. 
A estação chuvosa e de crescimento começa quando os totais decendiais de chuva se mostrarem maiores que a metade da evapotranspiração potencial, observou-se na (figura 5) começa no terceiro decêndio de novembro. Quando os totais decendiais de chuva forem menores que a metade da evapotranspiração potencial, termina a estação chuvosa, iniciando-se no terceiro decêndio de maio.

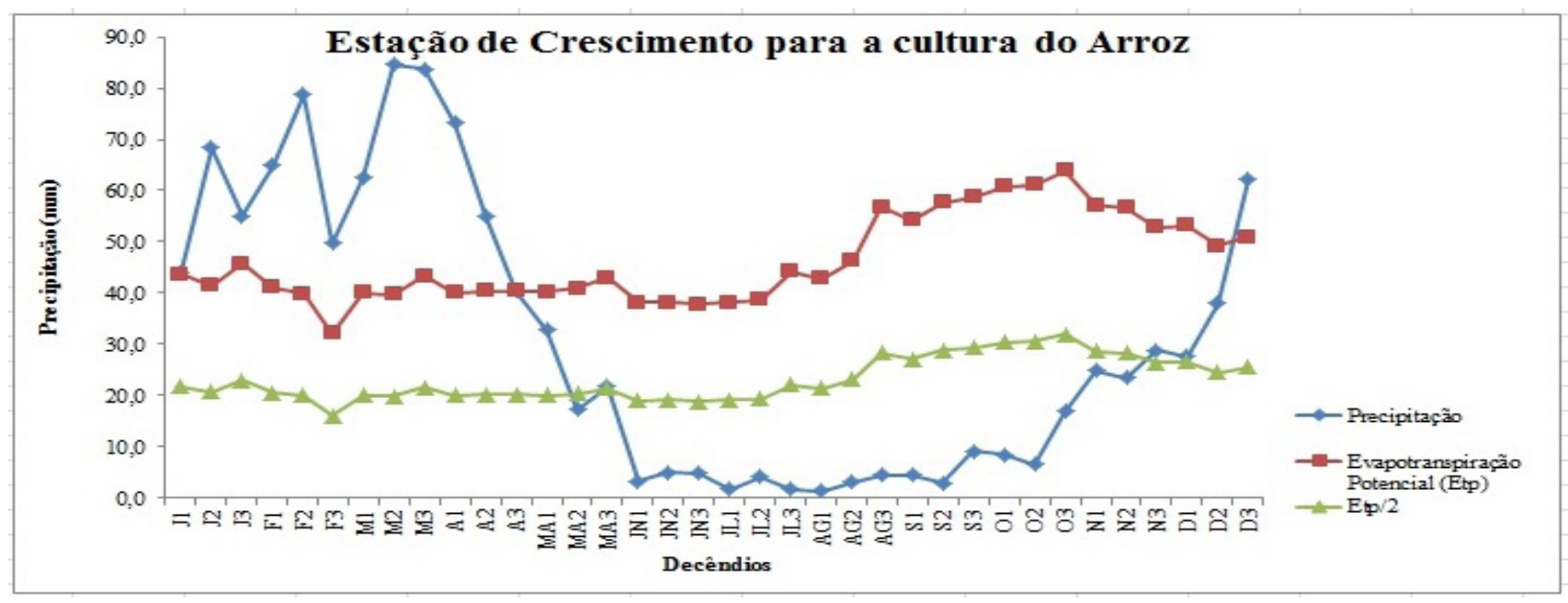

Figura 5 - Caracterização da estação de crescimento da região homogênea de precipitação R7 no estado do Maranhão.

A partir da caracterização da estação de crescimento foi realizada a análise de risco climático (Figura 6), onde o período favorável para a semeadura do arroz para a região homogênea de precipitação R7, considerando solo de textura arenosa com CAD de $20 \mathrm{~mm}$ vai desde o segundo decêndio de dezembro ao terceiro decêndio de janeiro, no qual os valores do ISNA se mantiveram acima de 0,65 , ideais para a semeadura do arroz. Considerando plantio em época de risco climático médio, o plantio do arroz nessa região pode ser plantado desde o terceiro decêndio de novembro até o segundo decêndio de fevereiro, para solos com CAD de $20 \mathrm{~mm}$. Efetivando o plantio do arroz após o terceiro decêndio de fevereiro, a produtividade do arroz pode ser severamente comprometida, pois os valores de ISNA estão abaixo de 0,55.

Considerando solo de textura areno-argilosa com CAD de $30 \mathrm{~mm}$, percebe-se que o período ideal para plantio do arroz nessa região se inicia no primeiro decêndio de dezembro ao primeiro decêndio de fevereiro no qual os valores do ISNA se mantiveram iguais ou acima de 0,65 . Considerando período de médio risco climático, o arroz pode ser semeado desde o terceiro decêndio de novembro até o segundo decêndio de fevereiro, com valores abaixo de 0,65.

Para solos com textura argilosa com CAD de $40 \mathrm{~mm}$, o período ideal se inicia desde o terceiro decêndio de novembro até o terceiro decêndio de fevereiro, no qual os valores do ISNA se mantiveram iguais ou acima de 0,65. Nenhum valor de ISNA nesta simulação ficou na época intermédia (valores entre 0,65 e 0,55 ) para solos com CAD de 40 mm. Estes resultados corroboram com os do Zoneamento Agrícola de Risco climático do MAPA (2017) para solos com CAD de 20 e 30 mm. No entanto, para solos com CAD de $40 \mathrm{~mm}$, o período de plantio do arroz vai desde o primeiro decêndio de novembro, estendendo-se até o terceiro decêndio de fevereiro. Segundo Souza (2003), é fundamental salientar que quanto maior a capacidade de armazenamento de água no solo, menor será o risco climático para a cultura da soja na sua fase de floração/enchimento de grãos. $\mathrm{O}$ mesmo pode ser aplicado para a cultura do arroz.

A região homogênea de precipitação R9 apresentou um período de estiagem, que começa a partir do primeiro decêndio de junho até o terceiro decêndio de dezembro (figura 7). A reposição de água no solo começa do primeiro decêndio de janeiro, estendendo-se até o segundo decêndio de fevereiro.

A retirada de água no solo ocorre desde o segundo decêndio de maio ao primeiro decêndio de setembro, estendendo-se a perda de água, começando então a deficiência de água no solo, indo até o terceiro decêndio de dezembro (figura 8). A reposição de água no solo ocorre no primeiro decêndio de janeiro e vai até o segundo decêndio de fevereiro. A partir do segundo decêndio de fevereiro ao primeiro decêndio de maio ocorre o excedente de água no solo

A estação chuvosa e de crescimento começa quando os totais decendiais de chuva forem maiores que a metade da evapotranspiração potencial. Observa-se na (figura 37) que a estação chuvosa começa no segundo decêndio de novembro. Quando os totais decendiais de chuva forem menores que a metade da evapotranspiração potencial, termina a estação chuvosa, que na figura 37, começa no primeiro decêndio de junho.

Após caracterizada a estação chuvosa e de crescimento, foi realizada a análise de risco climático para a região homogênea de precipitação R9 (figura 10). Considerando solo de textura arenosa com CAD de $20 \mathrm{~mm}$, o período favorável para a semeadura do arroz vai desde o terceiro decêndio de novembro, estendendo-se ao segundo decêndio de janeiro. Considerando plantio em 


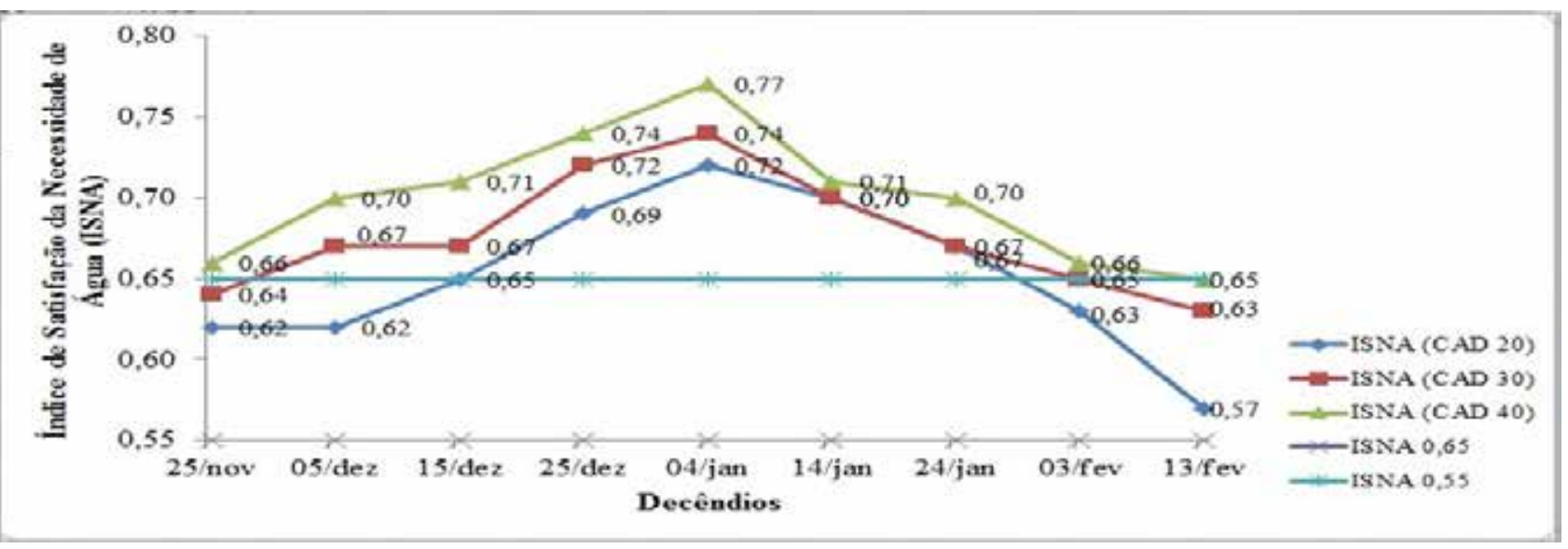

Figura 6 - Análise do ISNA para solos de textura arenosa com CAD de 20 mm, 30 mm e 40 mm na região R7 - Maranhão.

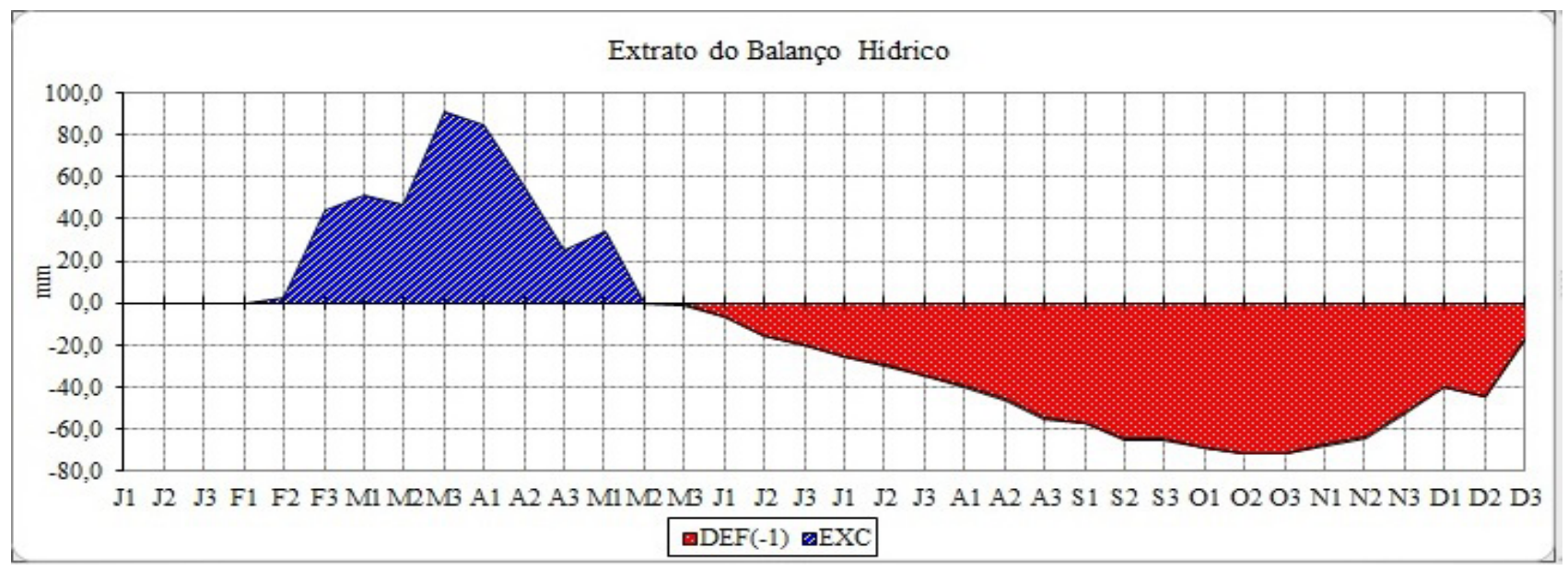

Figura 7 - Extrato do Balanço Hídrico Climatológico da região homogênea de precipitação R9, distribuídos em decêndios dos meses de janeiro a dezembro no estado do Maranhão.

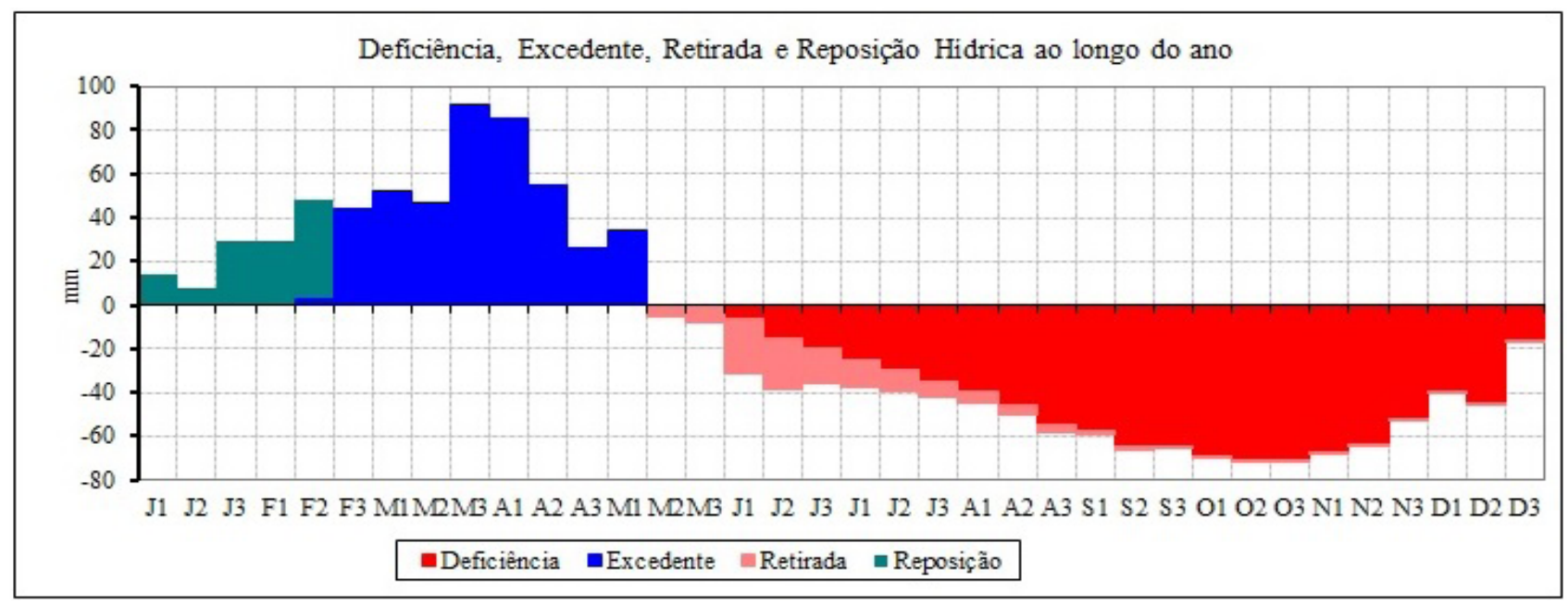

Figura 8 - Deficiência, Excedente, Retirada e Reposição hídrica ao longo dos anos na região homogênea de precipitação R9, dos meses de janeiro a dezembro, no estado do Maranhão. 


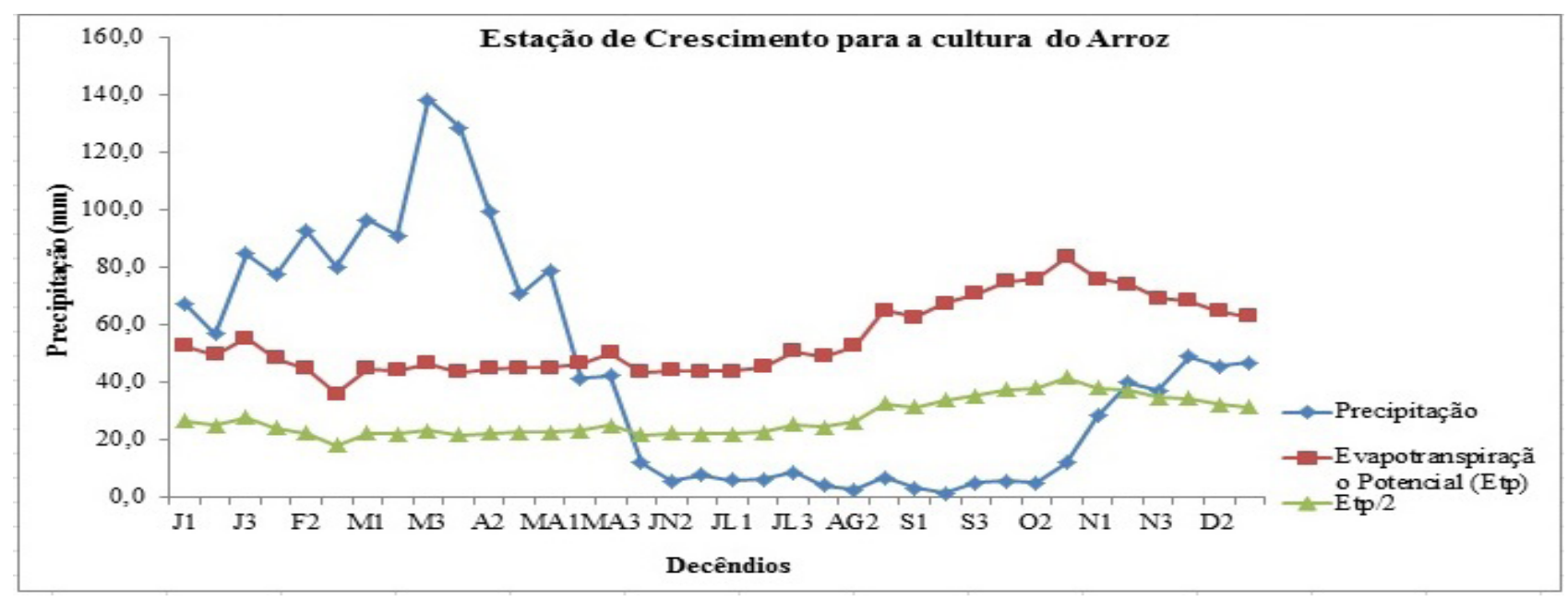

Figura 9 - Caracterização da estação de crescimento na região homogênea de precipitação R9 no estado do Maranhão.

época de risco climático médio, o plantio do arroz nessa região pode ser feito até o terceiro decêndio de janeiro, com valor de ISNA igual a 0,61 , isto para solos com CAD de $20 \mathrm{~mm}$. Efetivando o plantio do arroz em época após o segundo decêndio de janeiro, a produtividade do arroz pode ser comprometida, pois os valores de ISNA estão abaixo de 0,55.

A análise do ISNA para solos de textura areno-argilosa com CAD de $30 \mathrm{~mm}$ é possível verificar que o período ideal para plantio do arroz nessa região vai desde o terceiro decêndio de novembro ao segundo decêndio de janeiro. Considerando período de médio risco climático, o arroz pode ser semeado do segundo decêndio de novembro até o primeiro decêndio de fevereiro, com valores abaixo de 0,65 e maiores que 0,55 .

Para solos com textura argilosa com CAD de $40 \mathrm{~mm}$, o período ideal para a semeadura do arroz vai desde o terceiro decêndio de novembro até o terceiro decêndio de janeiro, no qual os valores do ISNA se mantiveram iguais ou acima de 0,65 . Para plantio no período de médio risco climático, o arroz pode ser semeado desde o segundo decêndio de novembro até o primeiro decêndio de fevereiro, com valores abaixo de 0,65 e maiores 0,55 .

Comparando com os resultados do MAPA (2017), diferiu um pouco quando ao período final da melhor época de semeadura do arroz, aonde o decêndio indicado pelo MAPA vai desde o segundo decêndio de novembro se estendendo até o segundo decêndio de fevereiro para solos com CAD de $20 \mathrm{~mm}$, e até o terceiro decêndio de fevereiro para solos com CAD de 30 e $40 \mathrm{~mm}$.

As áreas com baixo risco climático tenderam a serem maiores quando se assumiu como representativos os solos da região como do tipo 3, uma vez que apresentam maior capacidade de armazenamento de água em comparação aos solos dos tipos 1 e 2, pois em termos granulométricos possuem teores de argila superiores a $35 \%$ (ANDRADE JÚNIOR, BASTOS, 1997). Quando isso ocorre, a CAD do solo torna-se fator fundamental da definição da aptidão climática.

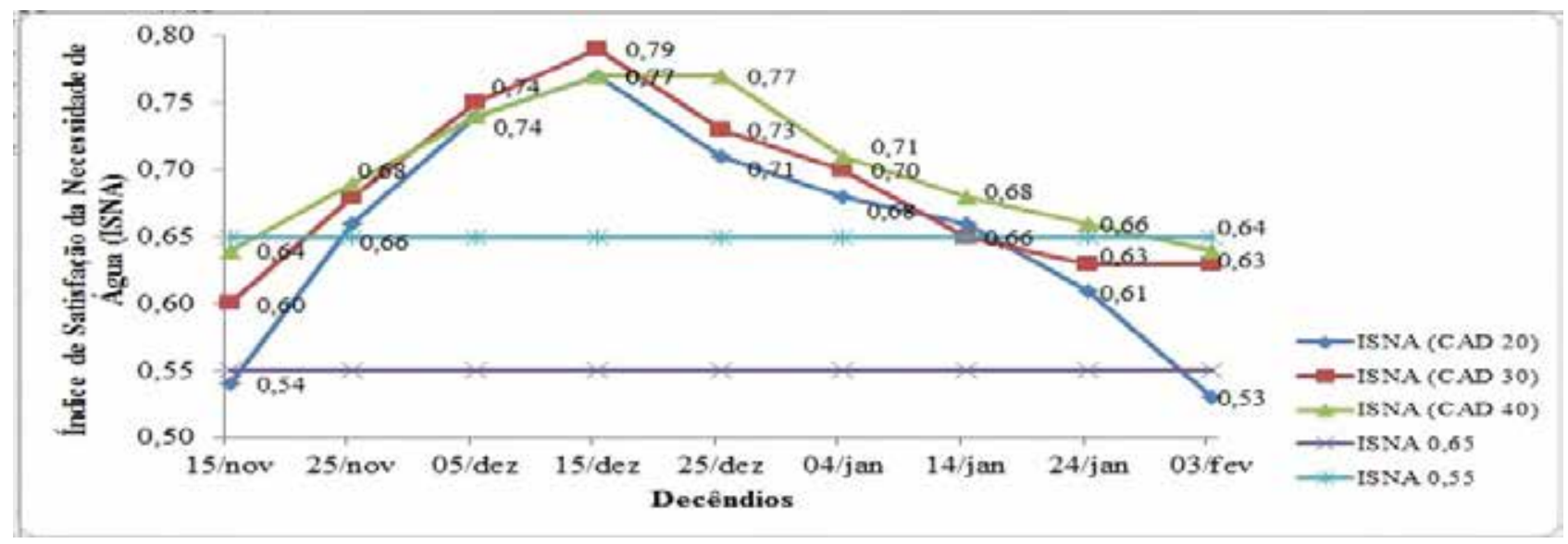

Figura 10 - Análise do ISNA para solos de textura arenosa com CAD de 20 mm, 30 mm e 40 mm na região R9 - Maranhão. 


\section{Conclusões}

Na região homogênea de precipitação R7, em solos com CAD de $20 \mathrm{~mm}$ a melhor época para a semeadura do arroz vai desde o segundo decêndio de dezembro ao terceiro decêndio de janeiro. Para solos com CAD de $30 \mathrm{~mm}$, o melhor período vai desde o primeiro decêndio de dezembro ao primeiro decêndio de fevereiro. E para solos com CAD de $40 \mathrm{~mm}$, a melhor época de plantio vai desde o terceiro decêndio de novembro ao terceiro decêndio de fevereiro.

As melhores épocas para a semeadura do arroz na região homogênea de precipitação R9 em solos com CAD de 20 e 30 $\mathrm{mm}$ vão desde o terceiro decêndio de novembro ao segundo decêndio de janeiro. Para solos com CAD de $40 \mathrm{~mm}$, a semeadura vai desde o terceiro decêndio de novembro ao terceiro decêndio de janeiro.

Estes resultados indicam a necessidade de se adotar um manejo que aperfeiçoe o uso da água no solo, como o plantio direto, cultivo intercalar ou a irrigação, bem como o desenvolvimento de cultivares mais tolerantes à deficiência hídrica.

Portanto, sugere-se que o uso dos procedimentos propostos para a definição das épocas preferenciais de semeadura do arroz de sequeiro passe a ser adotado como um critério mais seguro não só para os produtores rurais, mas também para os órgãos de financiamento e seguro agrícola.

\section{Referências}

ANDRADE JÚNIOR AS, BASTOS EA. Precipitação pluviométrica provável em municípios do Cerrado Piauiense. Teresina: Embrapa-CPAMN, 1997. 22p.

ARAÚJO AES. Caracterização e uso de bactérias diazotróficas isoladas de diferentes cultivares de arroz originárias do estado do Maranhão. [Thesis]. Rio de Janeiro: UFRRJ; 2008. 99 f.

ASSAD ED, EVANGELISTA BA, SANS LMA, FARIAS JR, SILVA SC. Zoneamento agroclimático para grãos na região do Meio-Norte Brasileiro. In: Simpósio Sobre Os Cerrados Do Meio-Norte. 1997. v. 1. pp. 20-38.

BARON C, PEREZ P, MARAUX F. Sarrazon - Bilan hidrique applique au zonage. Montpellier: Cirad.1996; 26p.

CARVALHO AL. Estação de cultivo baseada na precipitação pluvial diária e na ocorrência de períodos secos para a região de Rio Largo, Alagoas. [Dissertation]. Maceió: UFAL; 2010. $76 f$.

COMPANHIA NACIONAL DE ABASTECIMENTO (CONAB). [Internet], Brasília. Quarto levantamento. 2016. Disponível em: http://www.conab.gov.br/OlalaCMS/uploads/arquivos/ 16_01_12_09_00_46_boletim_graos_ janeiro_2016.pdf>. Acesso em: 10 out. 2017.

DOORENBOS J, KASSAM AH Yield response to water. Rome: Food and Agriculture Organization of the United Nations. Paper 33; 1979. 193 p.

DOURADO NETO D, JONG VAN LIER Q. Programa para elaboração do Balanço hídrico para culturas anuais e perenes. Manual do Usuário. Piracicaba: ESALQ; 1991.58 p.

EMPRESA BRASILEIRA DE PESQUISA AGROPECUÁRIA (EMBRAPA). [Internet]. Origem e História do Arroz. 2017. Disponível em: <http://www.cnpaf.embrapa.br/arroz/historia.htm>. Acesso em: 10 out. 2017.

LORENÇONI R, DOURADO NETO D, HEINEMANN AB. Calibração e avaliação do modelo ORYZA-APSIM para o arroz de terras altas no Brasil. Revista Ciência Agronômica, Fortaleza, 2010;41,4: 605-613.

MENEZES RHN. Caracterização agroclimática e análise do rendimento agrícola do estado do Maranhão. [thesis]. Campina Grande: UFCG; 2009. 181f.

MINISTÉRIO DA AGRICULTURA, PECUÁRIA E ABASTECIMENTO (MAPA). [Internet]. Zoneamento Agrícola de Risco Climático para a cultura de arroz de sequeiro no Estado do Maranhão, ano-safra 2017/2018. Disponível em: < http://www.agricultura.gov.br/assuntos/riscos-seguro/risco-agropecuario/portarias/safra-vigente/

maranhao $>$. Acesso em: 10 out. 2017. 
MINUZZI RB, SEDIYAMA GC, DA COSTA JMN, VIANELLO RL. Influência do El nino nas épocas de plantio e fenologia da cultura da soja na Região Sudeste do Brasil. Ceres, 2015;54, n. 313.

PEREIRA JAR. A Cultura do arroz no Brasil: Subsídios para sua história. Brasília: Embrapa Meio Norte, 2002. 226 p.

SENTELHAS PC, MONTEIRO JEBA. Agrometeorologia dos Cultivos: Informações para uma Agricultura Sustentável. In: José Eduardo B. A. Monteiro. (Org.). Agrometeorologia dos Cultivos: O Fator Meteorológico na Produção Agrícola. Brasília: Instituto Nacional de Meteorologia, 2009;1: 3-12.

SILVA GB, AZEVEDO PV. Potencial edafoclimático da "Chapada Diamantina" no Estado da Bahia para o cultivo de citrus. Revista Brasileira de Agrometeorologia, 2000;8, 1, pp.133-139.

SOUZA RAR. Comportamento de cultivares de arroz de terras altas em função do preparo do solo e irrigação por aspersão, em Latossolo vermelho de cerrado, Brasil. [dissertation]. Ilha Solteira: Faculdade de Engenharia/ UNESP;2003.69f.

STEINMETZ S, REYNIERS FN, FOREST F. Evaluation of the climatic risk on upland rice in Brazil. In: Colloque "resistence a la secheresse en millieu intertropicale: quelles recherches pour le moyen terme?" Paris: Cirad.1985. p. 43-54.

THORNTHWAITE CW. An Approach toward a Rational Classification of Climate. Geographical Review, 1948;38,1:55-94.

THORNTHWAITE CW, MATHER JR. The water balance: publications in climatology. New Jersey: Drexel Institute of Technology. 1955. 104p.

WANDER AE, CHAVES MO. [Internet]. Consumo aparente per capita de arroz no Brasil, 1991 a 2010. Congresso Brasileiro De Arroz Irrigado. 2001; Porto Alegre, 2001. Disponível: https://www.alice.cnptia.embrapa.br/ bitstream/doc/899182/1/se749.pdf. Acesso: 05 out. 2015.

Italo Ramon Januário
Universidade Federal de Alagoas, Brasil
Técnico em Meteorologia e Engenheiro Agrônomo
Email: italojanuario@hotmail.com
Participação do autor: como coletar e analisar os dados da cultura de arroz
associando com os dados climáticos para realizar o zoneamento
Ronaldo Nascimento Menezes
Universidade Estadual do Maranhão, Brasil
Graduado em Meteorologia
Email: rhmenezes@yahoo.com.br

Participação do autor: surgiu com a ideia inicial olhando pela necessidade de trabalhos deste tipo para o estado do Maranhão e o mesmo nos orientou para elaborar $\mathrm{o}$ artigo cuja a metodologia se baseia na tese de doutorado do professor Osmar Toledo Bonfim

Universidade Federal de Alagoas, Brasil

Mestrando em Meteorologia

Email: osmartoledob@gmail.com

Participação do autor: verificar a parte climática do trabalho, por exemplo, precipitação, temperatura, etc. como trabalhei com áreas homogêneas pude auxiliar nesta parte da metodologia. 